\title{
Order imbalance and stock returns: Evidence from China ${ }^{i s}$
}

\author{
Catherine Shenoy ${ }^{a}$, Ying Jenny Zhang ${ }^{b, *}$ \\ ${ }^{a}$ University of Kansas, School of Business, Lawrence, KS, USA \\ ${ }^{\mathrm{b}}$ Missouri State University, College of Business Administration, Finance and General Business Department, \\ Springfield, MO 65897, USA
}

Received 22 March 2007; accepted 6 September 2007

Available online 29 September 2007

\begin{abstract}
We investigate the relation between daily order imbalance and return in the Chinese stock markets of Shenzhen and Shanghai. Prior studies have found that daily order imbalance is predictive of subsequent returns. On the two Chinese exchanges we find the autocorrelation in order imbalances is similar to that of the New York Stock Exchange as reported by Chordia and Subrahmanyam [Chordia, T., \& Subrahmanyam, A. (2004). Order imbalance and individual stock returns: Theory and evidence. Journal of Financial Economics, 72, 485-518]. We also find a strong contemporaneous relation between daily order imbalances and returns. However, we do not find evidence that order imbalances predict subsequent returns. We attribute the difference in predicative power to differences in trading mechanisms on the two exchanges and to differences in the share turnover rates.
\end{abstract}

(C) 2007 Board of Trustees of the University of Illinois. Published by Elsevier B.V. All rights reserved.

JEL classification: G14; G15

Keywords: Stock exchange; Market efficiency; China

\section{Introduction}

Measures of daily order imbalances provide more information than volume alone about price formation and returns. Recent studies on the U.S. and Taiwanese stock markets both show that

\footnotetext{
This project has been funded by research grants from University of Kansas General Research Fund and from the Center for International Business Education and Research. KU CIBER is supported in part with funds from US Department of Education under Title VI of the Higher Education Act.

* Corresponding author. Tel.: +1 4178365348 ; fax: +1 4178366224 .

E-mail address: yjennyzhang@missouristate.edu (Y.J. Zhang).
} 
information about the relative number of buyer-initiated vs. seller-initiated trades in the market is related to return. More buyer (seller)-initiated trades may indicate either positive (negative) private information or herding behavior as uninformed investors engage in momentum trading. Chordia and Subrahmanyam (2004) document a positive relation between order imbalance and stock return on the New York Stock Exchange, where significant autocorrelation and predictive power of order imbalance on subsequent returns have also been found. The authors attribute their results to informed traders splitting big orders over days to minimize the price impact and to market makers accommodating orders by offering favorable terms to reduce their own inventory risk. Lee, Liu, Roll, and Subrahmanyam (2004) find similar relationships between order imbalance and returns in the Taiwanese market where trading is conducted via an automated quote-driven system in the absence of designated market makers. These authors also provide evidence of herding among retail investors and argue that de facto market making by all market participants, especially in terms of non-marketable limit orders, helps alleviate order imbalance and leads to its correlation with returns.

The role of order imbalance has not been studied in the Chinese stock market yet. In this paper, we fill this void by investigating the relation between order imbalance and return in the two Chinese markets of Shenzhen and Shanghai. Using tick data from two exchanges for the six-month period from July to December 2004, we find a strong contemporaneous relation between order imbalances and returns. The magnitude of autocorrelation of order imbalance in China is similar to that of NYSE. However, in contrast to Chordia and Subrahmanyam (2004) we do not find that order imbalance is predictive of subsequent returns.

The lack of a predictive relation between order imbalances and returns in Chinese stock market is surprising because there are several reasons to think that Chinese markets are less efficient. A commonly held belief is that the Chinese markets have more naïve participants and that herding would be common. In addition, there are several Chinese exchange rules that might have an exacerbating effect on order imbalances and returns. First, all shares are subject to a daily $10 \%$ price change limit. ${ }^{1}$ Limits on price changes would tend to introduce more autocorrelation, and one would expect a higher degree of predictability around information events. Second, short selling is prohibited on Chinese Stock Exchanges. This prohibition may induce additional autocorrelation in both returns and order imbalances. Stocks that investors think have good prospects may be bid up to higher levels without the counterbalance of short sellers who also provide some information to the market. Third, Chinese stock markets have very high share turnover rates despite relatively high transaction costs and a small asset float, especially for some large state-owned enterprises. ${ }^{2}$ The high share turnover rate has been attributed to a preponderance of small, naïve investors, who would tend to engage in speculative trading and herding behavior. That type of investor would increase the relation between imbalance measures and subsequent returns.

The rest of the paper is organized as follows. Section 2 reviews key aspects of the Chinese stock markets that may affect the order imbalance-return relation. Section 3 describes the data. Section 4 presents the results of the analyses. Section 5 concludes. Since this paper is the first to

\footnotetext{
${ }^{1}$ Regulations on price limits vary across time periods. Since December 1996 and during our sample period, the limit has been a $10 \%$ change with respect to previous day's closing price.

${ }^{2}$ Until 2006 state ownership dominated total market capitalization in China. For many state owned enterprises there are many fewer tradable shares than restricted shares. Market capitalization can be very different for firms with a large number of restricted shares depending on whether tradable shares or total shares are used to compute market capitalization. We use tradable shares in our calculations.
} 
utilize Chinese Stock Exchange tick data to our knowledge, we provide detailed description and evaluation of the data in Appendix A.

\section{Background and research issues}

\subsection{Market structure in China}

China's stock market began in the 1930s, but the market was shut down in 1949 when the civil war ended and the Communist party took control of the country. In 1990, as part of the reform agenda, stock exchanges in Shanghai and Shenzhen were formed and trading started in early 1991. Since then these two exchanges have grown rapidly in terms of number and types of listed securities and market value. By the end of 2006, the Shanghai Stock Exchange was ranked 19th worldwide, surpassing the Taiwanese and Singapore exchanges in Asia.

The Shanghai and Shenzhen Stock Exchanges are open five days a week from 9:30 a.m. to 3 p.m. with a trading break from 11:30 a.m. to 1:00 p.m. daily. In addition there is a pre-trading auction from 9:00 to 9:30 each morning during which orders are submitted and batched for execution using an equilibrium price as the opening price. The method is also called the Itayose method and is used on the Tokyo Stock Exchange (see Xu, 2000). A continuous price and time priority electronic auction matches all of the rest of the orders during the day, including orders accumulated over the lunch break. All market participants are able to see the five latest orders, bid/ask prices and trading volume. Orders are only valid for one day, and only market and limit orders can be placed.

There are two share types in China, A shares and B shares. An issuing firm can have one, or both share types. "A" shares clearly dominate the market with respect to number of shares issued, market capitalization, and trading activity. Investor demographics for A shares and B shares are very different. Until early 2001, B shares were restricted to foreign investors, typically foreign institutions; A shares were restricted to domestic investors. A shares became available to selected foreign investors in 2005. In this paper, we study A shares only.

There is some evidence to suggest that the primary market participants in the A share markets are individuals. The Shanghai Stock Exchange reports 37.9 million accounts in 2004. Of those, 36.8 million were retail accounts (Shanghai Stock Exchange, 2004). ${ }^{3}$ Fernald and Rogers (2002) argue that $A$ shares are mainly held by retail investors because there are few large Chinese institutional investors. Individual investors are assumed to be speculative investors. However, we are not aware of any data that document the type of trader as in the Lee et al. (2004) study. In fact a study by Green (2003) argues that Chinese markets are not dominated by small investors. He reports that the number of individual accounts is far fewer than official figures. He argues that there is double counting in each exchange, that individuals often open accounts to participate in an IPO and never trade again, and that there are a significant number of fraudulent or dummy accounts used as trading vehicles for wealthy individuals and institutions.

Another feature of the Chinese markets is that turnover is many times higher than a broad cross-section of other markets. Table 1 provides information about the size and turnover in a variety of markets. ${ }^{4}$ It shows that based on market value, the total Chinese market capitalization is smaller than six of the seven other exchanges. However, traded value and volume are higher

\footnotetext{
${ }^{3}$ reports similar number of accounts in 2004, most of which are assumed to overlap with Shanghaj.

4 data in Table 1 were collected from each of the stock exchanges websites or annual reports.
} 


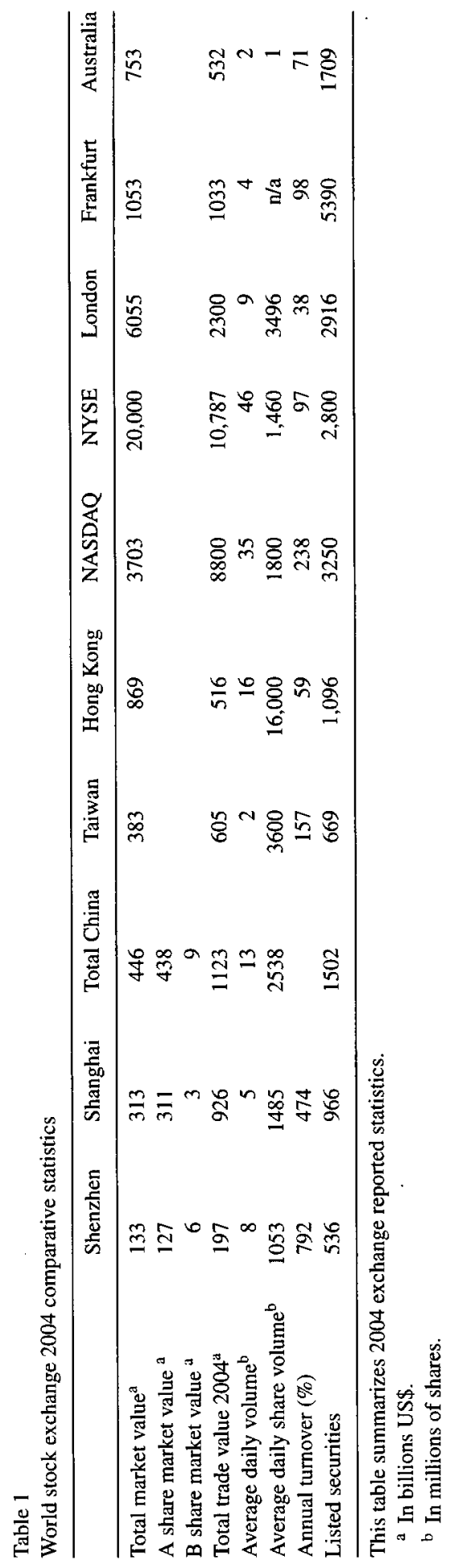


than all the exchanges reported except for those in the U.S. and the London exchange. As a result, both Chinese Stock Exchanges have very high annual turnover. Turnover for these markets are calculated based on the number of tradable shares.

In China, stocks can be listed either on the Shanghai or the Shenzhen Stock Exchange, but not both. In addition there are relatively stringent listing requirements. Some of the requirements in common at the Shanghai and Shenzhen exchanges are:

- minimum three-year operating history with positive earnings and a good credit record in each of the past three years;

- market capitalization must be at least RMB 50 million; and

- publicly traded shares must be more than $25 \%$ of the equity value.

As mentioned earlier, there is a price change limit in effect on both exchanges where prices cannot change more than $10 \%$ from the previous day's closing price in either direction in one day. Trading in a stock is not halted, but no orders can be processed unless they are within the daily limit. Daily price limit changes are fairly common. Austria, Finland, France, Italy, Japan, Korea, Mexico, the Netherlands, and Thailand all have some type of trading limits in place. Fama (1989) suggests that when the price discovery process is interrupted by price limits, there may be an increase in the underlying volatility and that the volatility may be spread out over a longer period. However, Chen, Rui, and Wang (2005) in a study of the Chinese markets finds that price limits decrease some price volatility, and they do not find that price limits interfere with the stock trading processes. Berkman and Lee (2002) examine price limits on the Korean Stock Exchange and find that the widening of price limits increases volatility and reduces trading volume. Order imbalance may be more predictive of returns in markets with price limits because one would expect increased serial correlation in order imbalances when price limits are in place. We investigate the effect of price limits on the relation between order imbalance and returns in Section 4.2 .

\subsection{Prior research on order imbalance and Chinese stock markets}

In their study of the volume-volatility relation on NYSE and NASDAQ stocks, Chan and Fong (2000) find that order imbalance has significant impact on returns across various sizes of trades and affects the volume-volatility relation accordingly:

Using tick data from the New York Stock Exchange, Chordia and Subrahmanyam (2004) study the order imbalance and return relation on a total of 2378 unique stocks during the 11-year span of 1988-1998. The study is motivated by risk-averse market makers who are concerned about adverse selection. These authors find that daily order imbalances lead returns and that trading strategies based on order imbalances may be profitable. They attribute the results to large traders who split orders over time and induce serial correlation in order imbalances.

Lee et al. (2004) also find some persistence in daily order imbalances in the Taiwan Stock Exchange. In the Taiwan Stock Exchange there are no dealers or specialists; trades are matched electronically just as in China. Their data also identify the types of traders, e.g., foreign vs. domestic, institution vs. retail. These authors find support for both herding and order splitting explanations of serially correlated order imbalances.

Theoretical models developed by Ho and Stoll (1981) and Spiegel and Subrahmanyam (1995) predict prolonged pricing pressures caused by institutional traders. The Chordia and Subrahmanyam (2004) study supports this idea. In addition, Hirshleifer, Subrahmanyam, and 
Table 2

Sample selection criteria and sample size

\begin{tabular}{llll}
\hline & Shenzhen & Shanghai & Total \\
\hline Number of listed stocks by June 30, 2004 & 505 & 826 & 1331 \\
Step 1. Stocks with at least 120 trading day history prior to July 2004 & 484 & 761 & 1245 \\
Step 2. Stocks that have less than 5 non-trading days during July-December 2004 & 472 & 744 & 1216 \\
Step 3. Stocks that have less than 5 bad tick-data days during July-December 2004 & 472 & 741 & 1213 \\
\hline
\end{tabular}

Table 3

Market capitalization for the Shenzhen and Shanghai Stock Exchanges

\begin{tabular}{lrr}
\hline & Shenzhen & Shanghai \\
\hline Mean market capitalization & 901 & 977 \\
Median market capitalization & 577 & 588 \\
Standard deviation of market capitalization & 1,016 & 1,445 \\
Maximum & 12,214 & 16,810 \\
75 th percentile & 1,024 & 990 \\
25th percentile & 387 & 377 \\
Minimum & 100 & 60 \\
Range & 12,114 & 16,750 \\
\hline
\end{tabular}

Market capitalization is the daily value during June 2004, measured in millions of RMB.

Titman (1994) argue that herding behavior by naïve investors may also induce a similar empirical relation.

A few studies directly investigate trading patterns in the Chinese stock market. Feng and Seasholes (2004) and Tan, Chiang, Mason, and Nelling (in press) both provide evidence for herding behavior, but Demirer and Kutan (2006) do not.

\section{Data}

We obtained tick data from Sinofin's CCER Tick Database from July to December 2004. We study all A share trading on both exchanges in the two daily general sessions. Our data do not include block trades. ${ }^{5}$ We begin in July 2004 because the method of data collection changed at that time. To be included in our sample stocks had to meet the following criteria:

(1) at least 120 trading day history before July 2004 ,

(2) no more than 5 non-trading days in our sample period, and

(3) no more than 5 bad tick-data days during the sample period. ${ }^{6}$

The final sample includes 1213 stocks from both exchanges. Table 2 shows the resulting sample size and the number of firms eliminated in each step.

Table 3 shows the statistics on market capitalization for the resulting sample. We calculate market capitalization using only tradable shares and report the cross-sectional statistics of sample

\footnotetext{
${ }^{5}$ Block trades, by official definition, are trades larger than 10,000 RMB and 10,000 shares. Block trades are transacted separately after the daily general sessions. They are not included in our analysis.

${ }^{6}$ We check the validity of tick data by comparing the aggregated volume of tick data with the exchange reported daily value; see Appendix A for more detail on these data checks.
} 
firms' daily averages during June 2004. The Shanghai exchange has slightly higher mean and median market capitalization than Shenzhen, but it also has a wider range and standard deviation. The market capitalization is skewed by a few large firms on both exchanges. However these are still very small firms from a global perspective. The 75 th percentile has approximately US\$125 million in market capitalization, and the largest firm has approximately US\$ 2 billion in market capitalization.

All transactions have been indicated as either buyer or seller-initiated trade from the exchanges, and we use those as indicators to calculate the imbalance measures in two ways. ${ }^{7}$ One is based on the total number of trades (OIBNUM) and the other is based on the RMB value of the trade (OIBVAL). The variables are calculated for each stock on each trading day and are defined as follows:

OIBNUM is the estimated daily number of buyer-initiated trades minus seller-initiated trades divided by the total number of trades for the day.

OIBVAL is the estimated daily value of buyer-initiated trades minus the value of the sellerinitiated trades divided by the total RMB value of trades for the day.

Table 4 shows the descriptive statistics for the daily imbalance measures for both exchanges and the relative size of the imbalances. The average order imbalance in Shanghai in terms of number of trades is -3.81 and -1.32 in Shenzhen. The average value of the daily order imbalance is $-176,000$ RMB in Shanghai and -40,160 RMB in Shenzhen, indicating more days with selling pressure during the sample period. The standard deviations are high on both exchanges indicating that there are many days with very high order imbalances.

Panel B of Table 4 presents the correlations among the variables on both exchanges. The magnitude of the correlations is similar in each exchange. In addition, these correlations are similar in magnitude to those reported in Chordia and Subrahmanyam (2004), except for the correlations between return and the imbalance in the number of transactions. For instance, we find that scaled order imbalance measured by trading volume has a correlation value with the stock return of 0.31 for both Chinese exchanges, which is comparable to 0.37 reported by Chordia and Subrahmanyam (2004). When order imbalance is measured using scaled number of transactions, however, our results differ from the previous study substantially. Chordia and Subrahmanyam (2004) find the scaled transaction imbalance has a correlation value with return of 0.34 . We find that the same correlation pairs are insignificant at 0.06 and 0.07 at Shanghai and Shenzhen, respectively. We attribute the difference in magnitude and significance to trade aggregation in the Chinese exchanges. We discuss this issue in more detail in Appendix A. Panel C of Table 4 provides autocorrelation in order imbalance measures up to five lags. The magnitude of autocorrelation in our sample is comparable to reported figures of Chordia and Subrahmanyam (2004).

\section{Results}

In the rest of the paper we report only the results using order imbalance measured by volume.

\footnotetext{
7 We rely on two variables from the exchanges for assigning buy vs. sell for each trade, "volume in" and "volume out". A buyer-initiated trade increases cumulative volume out whereas a seller-initiated trade increases cumulative volume in.
} 


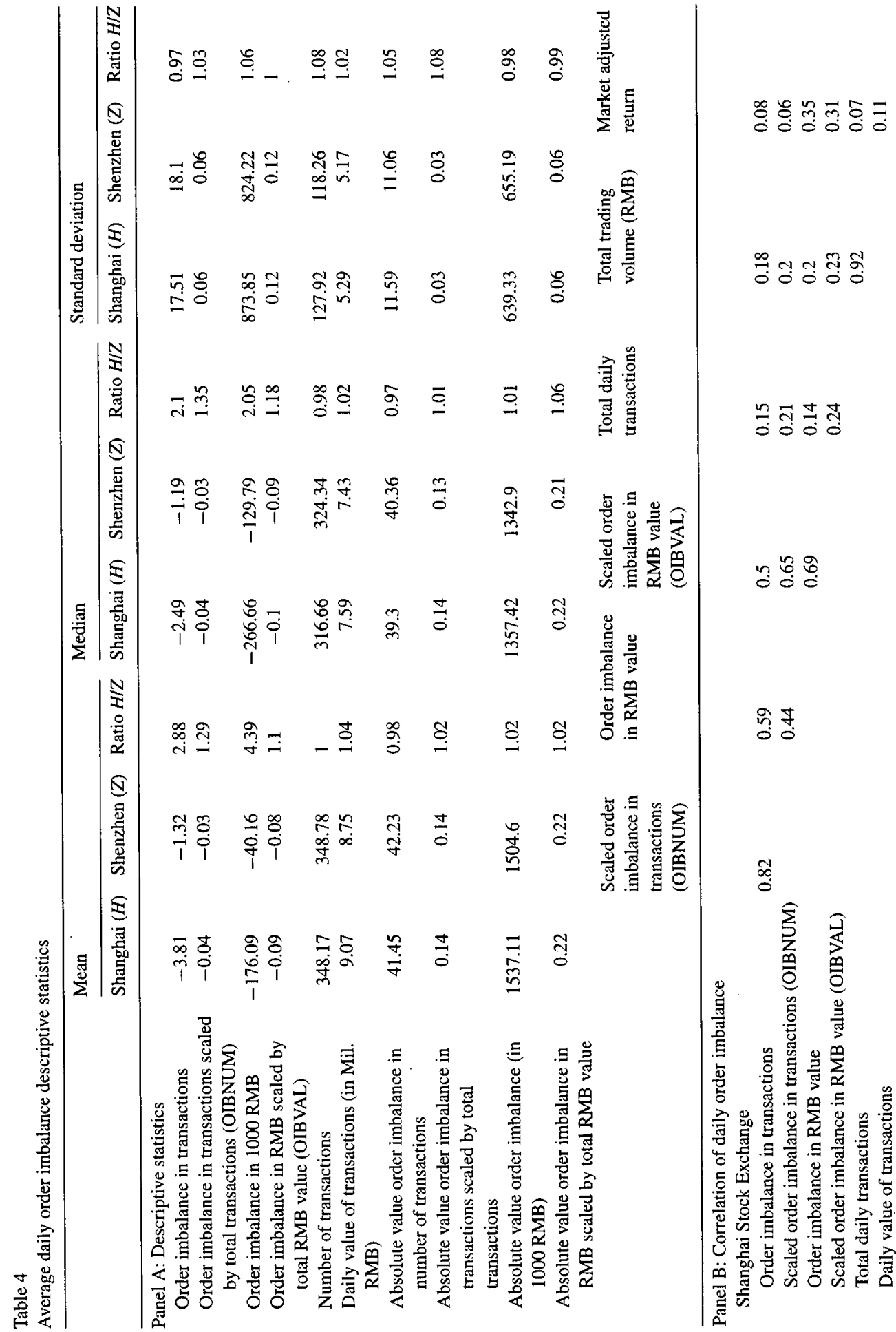




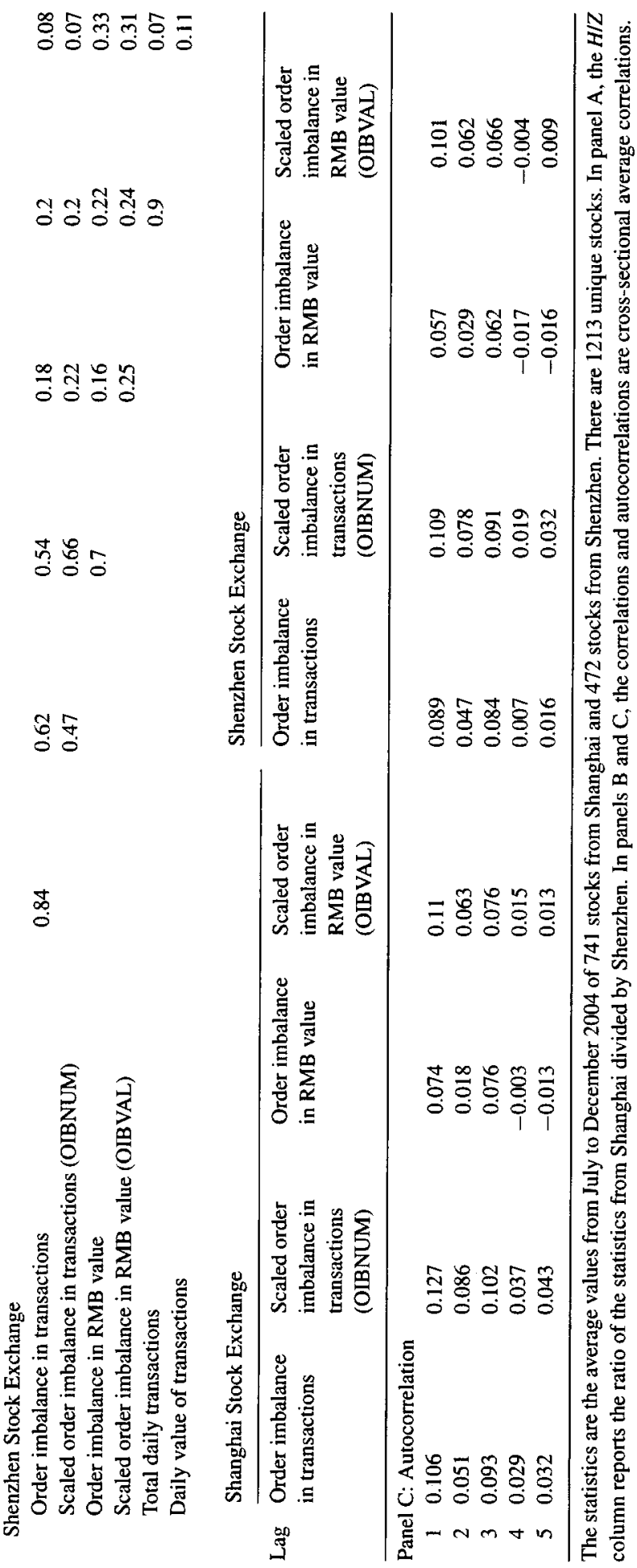


Table 5

Daily regression of open-to-close excess returns on contemporaneous and lagged order imbalances

\begin{tabular}{|c|c|c|c|c|c|}
\hline Variable & $\begin{array}{l}\text { Average } \\
\text { coefficient }\end{array}$ & $\begin{array}{l}\text { Percent } \\
\text { positive }\end{array}$ & $\begin{array}{l}\text { Percent positive } \\
\text { and significant }\end{array}$ & $\begin{array}{l}\text { Percent negative } \\
\text { and significant }\end{array}$ & $\begin{array}{l}\text { Percent significant } \\
\text { coefficients }\end{array}$ \\
\hline $\mathrm{OIB}_{i t}$ & $2.60(3.58)$ & 98.19 & 81.86 & 0.00 & 81.86 \\
\hline $\mathrm{OlB}_{i t-1}$ & $-0.31(-0.44)$ & 34.21 & 0.66 & 6.84 & 7.50 \\
\hline $\mathrm{OIB}_{i t-2}$ & $-0.21(-0.34)$ & 37.76 & 0.82 & 5.85 & 6.68 \\
\hline OIB $_{i t-3}$ & $-0.11(-0.18)$ & 43.12 & 1.81 & 4.04 & 5.85 \\
\hline OIB $_{i t-4}$ & $0.03(0.07)$ & 53.83 & 3.13 & 1.90 & 5.03 \\
\hline Average $R^{2}$ & 0.16 & & & & \\
\hline Average Adj. $R^{2}$ & 0.11 & & & & \\
\hline
\end{tabular}

This table reports the cross-sectional average coefficients from the. time-series regression for each stock. $R_{i t}-R_{\mathrm{mt}}=a+b_{1} \mathrm{OIB}_{i t}+b_{2} \mathrm{OIB}_{i t-1}+b_{3} \mathrm{OIB}_{i t-2}+b_{4} \mathrm{OIB}_{i t-3}+b_{5} \mathrm{OIB}_{i t-4}+e_{i t}$; OIB is the estimated daily value of buyer-initiated trades minus the value of the seller-initiated trades divided by the total RMB value of trades for the day. The coefficients are multiplied by 100 ( $t$-values reported in parentheses with each coefficient). Significance is reported at the $5 \%$ level.

\subsection{Daily time-series regressions}

We explore the time-series relation between daily returns and contemporaneous and lagged order imbalance. We expect that daily open-to-close returns should be related to imbalance measures. We construct a market average of the returns each day as our market benchmark, denoted $R_{\mathrm{mt}}$. The market average is an equally weighted index of all stocks for each exchange. The dependent variable in the regression is daily excess return, $R_{i t}-R_{\mathrm{mt}}$.

For each stock, $i$, we estimate the following regression:

$$
R_{i t}-R_{\mathrm{mt}}=a+b_{1} \mathrm{OIB}_{i t}+b_{2} \mathrm{OIB}_{i t-1}+b_{3} \mathrm{OIB}_{i t-2}+b_{4} \mathrm{OIB}_{i t-3}+b_{5} \mathrm{OIB}_{i t-4}+e_{i t}
$$

$R_{i t}$ is the open-to-close return on stock $i$ for day $t$. For stocks that trade on the Shanghai exchange we use the Shanghai market index of A shares, and for stocks that trade on the Shenzhen exchange we use the Shenzhen market index. OIB $i t$ is scaled order imbalance for stock $i$ on day $t$.

On average, positive returns should have more buyer-initiated transactions and negative returns should have more seller-initiated transactions. Therefore, we expect to see a positive relation between order imbalance and return. In Table 5 we see that $82 \%$ of time-series regression coefficients are positive and significant on the contemporaneous order imbalance term, but very few lagged coefficients are significant at the 5\% level. The results in Table 5 suggest that concurrent order imbalance positively affects return, as expected. However, lagged order imbalances are not significantly related to subsequent returns.

Table 6 reports the contemporaneous coefficients (i.e., $b_{1}$ ) from the daily time-series regression coefficients from Eq. (1) by size and turnover quartiles. Size is measured as tradable market capitalization, and turnover is measured as daily share volume divided by tradable shares. Both size and turnover are measured as the mean daily value during June 2004.

In panel A, all four size quartiles show similar values both on coefficients and $t$-values, which suggests size does not have significant bearing on the order imbalance and return relation. In panel B, we see a monotonic increase with turnover in the regression coefficients. Higher turnover stocks have larger coefficients, suggesting a stronger order imbalance and return relation. To the extent 
Table 6

Contemporaneous coefficients from regressions of excess return on order imbalances by size and turnover ranking

\begin{tabular}{|c|c|c|c|c|c|c|}
\hline Variable & $\begin{array}{l}\text { Average } b_{1} \\
\text { coefficient }\end{array}$ & $\begin{array}{l}\text { Average } \\
t \text {-value }\end{array}$ & $\begin{array}{l}\text { Percent } \\
\text { positive }\end{array}$ & $\begin{array}{l}\text { Percent positive } \\
\text { and significant }\end{array}$ & $\begin{array}{l}\text { Percent negative } \\
\text { and significant }\end{array}$ & $\begin{array}{l}\text { Percent significant } \\
\text { coefficients }\end{array}$ \\
\hline \multicolumn{7}{|c|}{ Panel A: Coefficients from regressions of excess return on order imbalances by size quartile } \\
\hline$Q 1 \mathrm{OIB}_{i l}$ & 2.49 & 3.61 & 99.01 & 79.87 & 0.00 & 79.87 \\
\hline$Q 2 \mathrm{OIB}_{i t}$ & 2.71 & 3.79 & 98.02 & 85.81 & 0.00 & 85.81 \\
\hline$Q 3 \mathrm{OIB}_{i t}$ & 2.76 & 3.74 & 98.68 & 84.87 & 0.00 & 84.87 \\
\hline$Q 4 \mathrm{OIB}_{i t}$ & 2.44 & 3.18 & 97.03 & 76.90 & 0.00 & 76.90 \\
\hline \multicolumn{7}{|c|}{ Panel B: Coefficients from regressions of excess return on order imbalances by turnover quartile } \\
\hline$Q 1 \mathrm{OIB}_{i t}$ & 1.70 & 2.65 & 95.31 & 66.25 & 0.00 & 66.25 \\
\hline$Q 2$ OIB $_{i t}$ & 2.26 & 3.37 & 98.43 & 80.88 & 0.00 & 80.88 \\
\hline Q3 OIB $_{i t}$ & 2.72 & 3.72 & 99.68 & 85.80 & 0.00 & 85.80 \\
\hline$Q 4 \mathrm{OIB}_{i r}$ & 3.94 & 4.43 & 99.22 & 90.59 & 0.00 & 90.59 \\
\hline
\end{tabular}

This table reports the cross-sectional average coefficients from each size (panel A) and turnover (panel B) quartile from the time-series regression for each stock. $R_{i l}-R_{\mathrm{ml}}=a+b_{1} \mathrm{OIB}_{i l}+b_{2} \mathrm{OIB}_{i t-1}+b_{3} \mathrm{OIB}_{i t-2}+b_{4} \mathrm{OIB}_{i t-3}+b_{5} \mathrm{OIB}_{i t-4}+e_{i t}$; OIB is the estimated daily value of buyer-initiated trades minus the value of the seller-initiated trades divided by the total RMB value of trades for the day. The coefficients are multiplied by 100 . Significance is reported at the $5 \%$ level. Size and turnover quartiles are based on mean daily market capitalization and turnover during June 2004. $Q 1$ is the smallest size (turnover) quartile and $Q 4$ is the largest size (turnover) quartile.

that higher turnover means more liquidity, we find that liquidity is an intermediating variable in the order imbalance and return relation.

\subsection{Order imbalance and price limits}

To investigate the effect of price limits on the order imbalance and return relation we define an indicator variable for each stock each day. The indicator variable, limit ${ }_{i t}$, is equal to 1 if the stock reaches the daily limit of $10 \%$ in either direction for stock $i$ on day $t$, and 0 otherwise. We estimate regressions for each stock as follows:

$$
R_{i t}-R_{\mathrm{mt}}=a+b_{1} \mathrm{OIB}_{i t}+b_{2} \text { OIB }_{i t} \times \text { limit }_{i t}+b_{3} \text { OIB }_{i t} \times \text { limit }_{i t-1}+e_{i t}
$$

The regression has interaction terms for contemporaneous order imbalance with today's price limit as well as with yesterday's price limit. The interaction terms allow us to investigate the possible effect of price limit on order imbalance and returns.

During the sample period, a total of 1071 stock-days with 546 unique stocks reached the $10 \%$ limit. This is $0.72 \%$ of the total stock-days in the sample. We estimate Eq. (2) regressions for the subsample of 546 stocks that reached the price limit in our sample period. The results are reported in Table $7 .^{8}$

Only the contemporaneous order imbalance coefficient is statistically significant on average. Our results suggest that price limit does not alter the imbalance-return relation, and even when the daily limit is reached in trading, prior order imbalance is not predictive of excess return on extreme days.

\footnotetext{
${ }^{8}$ Regressions including all the lagged order imbalance terms yield similar results to those reported in Table 7 . Since lagged order imbalance terms are not significant (similar to Table 6), we report only the results from Eq. (2). Full results are available on request.
} 
Table 7

Regression coefficients of open-to-close excess returns on order imbalances and price limits

\begin{tabular}{lcllll}
\hline & $\begin{array}{l}\text { Average } \\
\text { coefficient }\end{array}$ & $\begin{array}{l}\text { Average } \\
t \text {-values }\end{array}$ & $\begin{array}{l}\text { Percent significant } \\
\text { coefficients }\end{array}$ & $\begin{array}{l}\text { Percent positive } \\
\text { coefficients }\end{array}$ & $\begin{array}{l}\text { Percent positive } \\
\text { and significant }\end{array}$ \\
\hline OIB $_{i t}$ & 3.01 & 4.03 & 87.18 & 98.35 & 87.18 \\
OIB $_{i t} \times$ limit $_{i t}$ & 9.82 & 1.44 & 68.07 & 72.48 & 68.07 \\
OIB $_{i t} \times$ limit $_{i t-1}$ & 14.94 & 0.37 & 16.54 & 61.95 & 16.54 \\
Average $R^{2}$ & 0.22 & & & & \\
Average Adj. $R^{2}$ & 0.21 & & & & \\
\hline
\end{tabular}

This table reports the cross-sectional average coefficients from the time-series regression for each stock. $R_{i t}-R_{\mathrm{mt}}=a+b_{1} \mathrm{OIB}_{i t}+b_{2} \mathrm{OIB}_{i t} \times$ limit $_{i t}+b_{3} \mathrm{OIB}_{i t} \times$ limit $_{i t-1}+e_{i t}$; OIB is the estimated daily value of buyer-initiated trades minus the value of the seller-initiated trades divided by the total RMB value of trades for the day. Limit ${ }_{i t}$ is equal to one for stock $i$, if the price reaches the $10 \%$ limit on day $t$. The coefficients are multiplied by 100 . Significance is reported at the $5 \%$ level.

\section{Conclusion}

We investigated the relation between daily order imbalance and returns in Chinese stock markets of Shenzhen and Shanghai. Using tick data from the two exchanges we define daily order imbalance as the difference between buyer and seller-initiated trades. Prior studies by Chordia and Subrahmanyam (2004) and Lee et al. (2004) have found that daily order imbalance is predictive of subsequent returns on the New York Stock Exchange and to lesser extent on the Taiwanese Stock Exchange. The level of autocorrelation and other statistical measures of the order imbalances in Shanghai and Shenzhen are similar to that of the New York Stock Exchange reported by Chordia and Subrahmanyam (2004). We do find a strong contemporaneous relation between daily order imbalances and returns. However, we do not find that order imbalances predict subsequent returns overall or for any subset of stocks, even those with the largest daily price moves. We attribute the difference in predictive power of order imbalance on return to the difference in market structures and trading characteristics in terms of daily turnover. The New York Stock Exchange is a quote-driven specialist market, while both Chinese exchanges are order-driven markets that use computerized matching of orders on price and time priority. ${ }^{9}$ Chinese stocks have much higher turnover rates than U.S. and Taiwanese stocks. Our results partitioning on turnover suggest that higher turnover, which means better liquidity, is associated with a stronger order imbalance and return relation.

\section{Acknowledgements}

The authors wish to thank two anonymous referees, the editor, Dr. Gordon J. Alexander, and seminar participants at the University of Kansas, 2007 MFA meetings, for their valuable suggestions that greatly improved this paper.

\section{Appendix A. Additional data evaluation and description}

In this appendix, we provide a detailed description and an evaluation of the tick data used in our paper. We used the CCER Tick Database through the data vendor, Sinofin Inc., an affiliate

\footnotetext{
${ }^{9}$ NYSE has been in gradual shift to computerized trading in recent time and completed this transition in January 2007. See ref. Lucchetti (2007).
} 
to CCER (Center for China Economical Research) at Beijing University. These data are of the highest quality among publicly available data sources; however, it is not without inevitable limitations. The reasons for limitations are due to two sources: first, there is some aggregation in reporting trades, and second, there is some question about daily price limit enforcement and/or reporting.

\section{A.1. Trade aggregation}

Unlike tick data in the U.S. that the NYSE and NASDAQ provide through TAQ and NASTRAQ, respectively, the two official Chinese exchanges have not started such services. Instead, the two exchanges update quote and trade information to all subscribers through satellite services at 5-s intervals. Since the exchanges use an open limit order book, one would expect that for the most liquid stocks several different orders may come in and cross within the 5-s interval. The result is that some quotes and/or trades are aggregated when reported by the exchanges. We find that the number of transactions reported by the exchanges do not match the number of transactions accounted for in the CCER Tick Database.

Since the exchanges do not directly provide tick data, our data vendor Sinofin obtains their raw data from one of the subscribers that receive quote/trade update from the exchange every $5 \mathrm{~s}$. They screen and correct obvious errors.

To illustrate the trade aggregation issue, we compare the daily total trading (RMB) volume and daily total number of transactions reported by official exchanges to daily aggregated values based on the tick data. For each stock we calculate the daily volume in RMB and the number of transactions by aggregating the transaction number and amounts for each day. We find that there is very little difference between the two sources in terms of trading volume (RMB), with the mean (median) difference of $-0.01 \%(0.00 \%)$. However, with respect to number of transactions, the difference between the two sources is substantial. The mean (median) percentage difference stands at $50.23 \%(49.41 \%)$. Such a large difference suggests substantial trade aggregation in the tick data. We believe this trade aggregation issue makes any interpretation of data using the number of transactions subject to question.

\section{A.2. Price limits}

China has limits on daily price movement of stocks. Orders that come in that are more than $10 \%$ above or below the previous day's closing price are not filled. Once the $10 \%$ limit is reached, trading can still be conducted on orders that are within the limit. However, upon inspection of the tick data, we do detect some price movements that are greater than $10 \%$ of the previous day's close, some are even quite large. During the sample period, a total of 1071 stock-days with 546 unique stocks hit the $10 \%$ limit, which counts for $0.72 \%$ of the total stockdays.

\section{A.2.1. Holidays and unusual days}

During our sample period, July 1, 2004 to December 31, 2004, there are 127 trading days in China. The stock market closed for a week from October 1 to 7 for the Chinese National holiday. In addition to holidays, the tick data for the Shanghai exchange is missing on October 8 , October 11, and December 2. The tick data are missing for the Shenzhen exchange on December 2. July 19 is also an unusual day because only 95 stocks were traded on the Shenzhen exchange. 


\section{References}

Berkman, H., \& Lee, J. B. T. (2002). The effectiveness of price limits in an emerging market: Evidence from the Korean Stock Exchange. Pacific-Basin Finance Journal, 10, 517-530.

Chan, K., \& Fong, W. M. (2000). Trade size, order imbalance, and the volatility-volume relation. Journal of Financial Economics, 57, 247-273.

Chen, G. M., Rui, O. M., \& Wang, S. (2005). Price limits and stock characteristics: Evidence from the Shanghai and Shenzhen Stock Exchanges. Review of Quantitative Finance and Accounting, 25, 159-182.

Chordia, T., \& Subrahmanyam, A. (2004). Order imbalance and individual stock returns: Theory and evidence. Journal of Financial Economics, 72, 485-518.

Demirer, R., \& Kutan, A. M. (2006). Does herding behavior exist in Chinese stock markets? Journal of International Financial Markets, Institutions and Money, 16, 23-142.

Fama, E. F. (1989). Perspectives on October 1987 or what did we learn from the crash? In J. R. W. Kamphuis, R. C. Kormendi, \& J. W. H. Watson (Eds.), Black Monday and the future of financial markets. Homewood, IL: Irwin.

Feng, L., \& Seasholes, M. S. (2004). Correlated trading and location. Journal of Finance, 59, 2117-2144.

Fernald, J., \& Rogers, J. H. (2002). Puzzles in the Chinese stock market. The Review of Economics and Statistics, 84, 416.

Green, S. (2003). China's stock market: Eight myths and some reasons to be optimistic. The China Project (p. 24). London: The Royal Institute of International Affairs/Cambridge University.

Hirshleifer, D., Subrahmanyam, A., \& Titman, S. (1994). Security analysis and trading patterns when some investors receive information before others. Journal of Finance, 49, 1665-1698.

Ho, T., \& Stoll, H. (1981). Optimal dealer pricing under transaction and return uncertainty. Journal of Financial Economics, 9, 47-73.

Lee, Y. T., Liu, Y. J., Roll, R., \& Subrahmanyam, A. (2004). Order imbalances and market efficiency: Evidence from the Taiwan Stock Exchange. Joumal of Financial and Quantitative Analysis, 39, 327-341.

Lucchetti, A. (2007). The NYSE: Faster (and Lonelier); Historic electronic-trading shift means swift service for investors, 'painful' time for brokers on the floor. The Wall Street Journal, 27(January), C.1.

Shanghai Stock Exchange. (2004). Fact Book 2004 Shanghai securities market. Shanghai: Shanghai Stock Exchange.

Spiegel, M., \& Subrahmanyam, A. (1995). On intraday risk premia. Journal of Finance, 50, 319-339.

Tan, L., Chiang, T. C., Mason, J., \& Nelling, E. (in press). Herding behavior in Chinese stock markets: An examination of A and B shares. Pacific-Basin Finance Journal.

Xu, C. K. (2000). The microstructure of the Chinese stock market. China Economic Review, 11, $79-97$. 


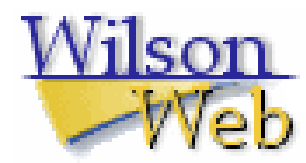

\section{COPYRIGHT INFORMATION}

TITLE: Order imbalance and stock returns: Evidence from China SOURCE: Q Rev Econ Finance 47 no5 2007

The magazine publisher is the copyright holder of this article and it is reproduced with permission. Further reproduction of this article in violation of the copyright is prohibited. To contact the publisher: http://www.uiuc.edu/ 